\title{
Micotoxinas, mielopatías y mucho más en, para y desde Colombia
}

El estudio de la micotoxicosis humana, en Colombia, es aún escaso (1), a pesar de lo investigado y publicado en, para y desde Colombia como veremos a continuación.

Hace cerca de una década encontramos nivalenol y deoxinivalenol en la orina de pacientes con paraparesia espástica tropical (PET) quienes vivían en el suroccidente colombiano, siendo algunos de ellos seropositivos para el HTLV-I (2). Igualmente, se encontró una correlación entre micotoxinas y ausencia de sistemas adecuados de almacenamiento y refrigeración de alimentos en poblaciones afectadas por PET $(3,4)$. Mas aún, se demostró una relación entre ésta enfermedad y cambios climáticos no solo en Colombia, sino en otras latitudes donde dicha patología era prevalente (5), estableciéndose relaciones entre virus, toxinas y medio ambiente (6). Estas investigaciones sirvieron, también, para avanzar en la comprensión de la encefaloneuromielopatía cubana (7); ilustrándose además, de manera amplia, la micotoxicosis como causa y consecuencia de trastornos asociados con malnutrición en pacientes susceptibles, principalmenteKwashiorkor (8).

Así mismo, se fundamentó la susceptibilidad a la intoxicación pormico-toxinas debido a trastornos genéticos diseminados alrededordel mundo desde hace siglos (9). También,se han correlacionado las micotoxinas con SIDA -con y sin VIH-, así como con otras entidades neurodegenerativas humanas que se confunden, en ocasiones, con supuestas infecciones virales lentas como el escrapie, kuru y la enfermedad de las vacas locas, entre otras (10-12).

Por todo esto, apoyamos los conceptos de Duarte-Vogel y Villamil-Jiménez (1) quienes afirmaron que las micotoxinas son un problema latente de salud pública en Colombia que, consideramos, debe ser analizado mucho más a fondo no solo por las entidades responsables del control de la misma sino, también, por los interesados en ayudar con el avance del conocimiento, identificación y control de estas viejas fieras que cada vez se presentan con nuevas y más soterradas mañas (13).

Fidias E. Leon-Sarmiento,

Uniciencia Research Group, Universidad Nacional de Colombia/Seccion de Neurologia, Fundacion

Santa Fe, Bogota, Colombia. E-mail: feleones@gmail.com

Jaime Bayona-Prieto

Universidad de Pamplona, Pamplona, Colombia

Marta E. Leon-S,Ph. D.

Unitropico, Yopal, Colombia 
1. Duarte-Vogel S, Villamil-Jiménez LC. Micotoxinas en la salud pública. Rev Salud Pública 2006; 8 (supl); 129-135.

2. Leon-S FE, Carpintero M, Gaffa N, Ocampo L, Bayona J. Mycotoxins in myelopathies of man. Lancet 1996; 348 :1039

3. Leon-S FE, Ocampo L, Bayona J, CarpinteroM,DelCastilloN. Refrigeración : otro cofactor en infecciones retrovirales. Acta Med Col 1996; 21 (suppl) : 226.

4. Leon-S FE, Carpintero M, Bayona J, Gaffga N, Ocampo L, Del Castillo N. La falta de refrigeración y la intoxicación por micotoxinas son cofactores fundamentales en la paraparesia espástica tropical. Rev Neurol 1998; 152: 564-567.

5.Leon-SFE, Carpintero M, DeMerinoNV. Meteorological conditions in HAM/TSP: ¿coincidence or clue? Rev Med Chile 1997; 125: 499-501.

6. Leon-S FE, Carpintero M, De Merino $\mathrm{N}$, Zaninovic V. Un brindis por un coctel neuropatológico de micotoxinas, retrovirus y paraparesia espástica. Salud-UIS 1996; 24: 3-7.
7. Leon-S FE, Acevedo A, Chavez AM. Micotoxinas y la encefaloneuromielopatia cubana. Inv Clin 1999; 40: 161-164.

8. Leon-S FE, Gaffga N. Nutritional rehabilitation in tropical neurology. In : Chopra JS, Sawhney IMS (eds). Neurology in Tropics. New Delhi: Churchill Livingstone; 1998. p. 16-23.

9. Leon-S FE, Ariza-Deleon A, Leon ME, Ariza-CA. Peopling the Americas. Science 1996; 273: 723-724.

10. 1er simposio internacional SIDA sin VIH, ¿mito o realidad?. Bucaramanga, 1997.[Ingternet]. Disponible en http:// www.free-news.org. Consultado: Octubre de 2006

11. Leon-Sarmiento FE (ed). ViH \& Los virus de la imaginación humana. Bogota: Celsus; 2001.

12. Leon-Sarmiento FE, Carpintero M. Retrovirus, micotoxinas, inmunosupresión y neurodegeneración. Rev Neurol 2002; 35: 562-571.

13. Leon-S FE. La micotoxicosis humana es una perra vieja con nuevas mañas. Neurociencias Col 1998; 6: 47-48. 